\title{
Sustainable regional social protection system
}

\author{
Natalia Suptelo ${ }^{1, *}$, Tatyana Sobol ${ }^{1}$, Ekaterina Rubtsova ${ }^{1}$, and Olga Fokina $^{2}$ \\ ${ }^{1}$ Moscow University named after S.Yu. Witte, 2nd Kozhukhovsky passage, 12, bld.1, Moscow, \\ 115432 \\ ${ }^{2}$ Vyatka State University, Moskovskaya str., 36, Kirov, 610000, Russia
}

\begin{abstract}
The purpose of this article is to develop directions for transforming the regional social protection system. The regions with a large imbalance in the population structure are very vulnerable. The study focuses on the analysis of the Yamal-Nenets Autonomous Okrug (YNAO), as it differs in a specific labor market with a large number of shift workers. The result of the study was the identification of priority areas for the regional social protection system development. The analyzed foreign experience also showed the need to involve retirees in the labor activity.
\end{abstract}

\section{Introduction}

Social policy is the main and most significant area in the implementation of state functions. Economy development, regulation of market relations, stimulation of economic growth all these actions of the state only create conditions for improving the welfare of the population and developing social infrastructure [1]. Insufficiently high rates of economic growth in the Russian Federation after the crisis of 2014-2015 have exacerbated the most acute social problems. Currently, the Russian Federation has quite low unemployment rates as well as inflation is relatively low compared to previous periods. At the same time, there is a large number of socially unprotected citizens. The complexity of the situation lies in the fact that in Russia the qualitative composition of socially vulnerable groups is completely different than in most other countries. So, while abroad the majority of socially unprotected segments of the population are represented by marginal elements, in Russia such groups are mostly represented by retirees, stagnant unemployed, low-skilled workers, and dysfunctional families. In Russia, there are no such concepts as 'ghetto' or 'marginal areas' [2]. Thus, the problem of supporting the socially vulnerable groups of the population is a nationwide task that concerns the entire society.

The role of regional social protection authorities in this situation is significant. Although the country's pension system is centralized, many social protection functions have been transferred to the regional level. Moreover, when there is a need for concrete actions by the social protection authorities, in direct contact with the population, the importance of the regional level of government grows.

The theme of population social protection is quite widely represented in the Russian scientific literature. However, most of the work focuses on the study of the issues of social policy as such. The regional aspect often remains outside the focus of attention of

\footnotetext{
* Corresponding author: nsuptelo@muiv.ru
} 
researchers. Thus, the relevance of the article is determined by the insufficient knowledge of the issues of population social protection at the regional level, considering local specifics.

The social policy in the Russian Federation is structured in such a way that the powers of the local government, the regional government and the federal center are strictly delimited. With a certain degree of conditionality, it can be said that the rights enshrined in the country's Constitution assigned to the federal center.

The implementation of other social guarantees is the prerogative of local authorities. In view of the fact that the federal level governs the most powerful instruments of social policy, it plays the most important role in distribution of financial resources. This has a number of implications for the regional level [3]. Thus, the pension system in the country and the functioning of the social infrastructure system are directly dependent on the macroeconomic situation, the costs of the federal budget. That is why regional differences in the level of social protection are not so great, even despite the difference in economic development of regions [4].

Social policy in the regions is always aimed at considering the factors of social processes formation specific for each region. Accordingly, this policy provides the introduction and implementation of regional social guarantees that extend or supplement federal guarantees [5].

Moreover, the regulation of social processes in individual territories and organizations will lead to the formation of a sustainable development of the region as a whole. In order to create a unified system of regional social processes regulation, it is necessary to coordinate the actions of all local authorities, as well as coordinate the efforts of organizations in the social protection of their employees. The result of such efforts will be to ensure social stability, which is the main task of social policy.

The regional level of the social protection system is identified with the responsibility of local authorities. However, at its core, the social protection system in different regions basically will be similar. It is important to note that any regional system of social protection in the Russian Federation is a component of the unified state system of social protection of the population. The nationwide model is built in such a way that its most important components are integrated at the state level. For example, the Pension Fund of the Russian Federation is one of such unified structures. In addition, the federal legislation is a fundament for the social sphere, the decisions of regional assemblies can only supplement it [6].

\section{Methods}

To identify the features of the social protection system, it is necessary to consider the structure of its formation. Using the example of a real region is more convenient to do this. However, large differences in the structure of regional economies, the size of budget allocations for social protection and the level of incomes in regions prevent generalizing the results for the whole country. Especially vulnerable are those regions where there is a large imbalance in the structure of the population. The social policy of such regions requires very specific measures.

For the purposes of this study, the Yamalo-Nenets Autonomous Okrug (YNAO) was chosen as an object. The YNAO's labor market is completely different from the whole country. So, in view of the fact that the main employers in the region are mining industries, many employees work on a rotational basis (shifted work) or move to the region temporarily.

Efforts to maintain a balanced social protection system depend on:

- the number of people in working age who makes tax deductions, 
- number of unemployed working aged people,

- income level,

- number of socially vulnerable citizens,

- and structure of social benefits.

This analysis is based on statistical data and gives an accurate idea of the current state of the system.

It is necessary to evaluate the effectiveness of existing measures taking into account risks in order to develop directions for transforming the regional social protection system.

\section{Results}

The YNAO is a federal subject of the Russian Federation, which is the part of the Tyumen Region. On 01-Jan-2019, the total population was 0.54 million people [7]. 76.1\% of the population are of working age (the average for Russia is 61.9\%). The demographic situation in the district is characterized by a steady natural population growth associated with the specific structure of the regional economy and a large number of temporary residents.

The basis of the economy of the YNAO is oil and gas production. Oil and gas condensate are produced by more than 30 enterprises, which attract workers on a rotational basis (shifted work). On 01-Jan-2019, the average salary in the region amounted to 86,560 rubles (3rd place in the Russian Federation) [8]. The number of unemployed citizens in the region is significantly lower than the corresponding indicator for the country as a whole and is only $0.6 \%$ (the average for the country is $4.9 \%$ ).

A distinctive feature of the YNAO is the age structure of the unemployed: more than half of the unemployed in the region are representatives of the age group up to 30 years, which is significantly different from the national ratio. Unlike the most other regions of the country, there are practically no unemployed people in the age group of 60 years, the unemployment is also low in the group of 50-60 years, which indicates the specificity in the organization of the labor market in the region (Table 1).

Table 1. Composition of the unemployed by age groups in the YNAO and in the Russian Federation as a whole (in \% of the total number of unemployed).

\begin{tabular}{|l|c|c|c|c|c|c|c|c|}
\hline & Total & \multicolumn{6}{|c|}{ Age } & Average \\
\cline { 3 - 9 } & unemployed & $\mathbf{1 5 - 1 9}$ & $\mathbf{2 0 - 1 9}$ & $\mathbf{3 0 - 3 9}$ & $\mathbf{4 0 - 4 9}$ & $\mathbf{5 0 - 5 9}$ & $\mathbf{6 0 - 7 2}$ & age \\
\hline Russia & 100 & 4.2 & 35.8 & 24.0 & 16.9 & 16.2 & 3.1 & 35.8 \\
\hline YNAO & 100 & 3.7 & 53.5 & 22.2 & 13.6 & 7.0 & - & 30.9 \\
\hline
\end{tabular}

At the same time, the situation with the number of socially unprotected citizens is in a special way. Upon reaching retirement age, people working on a rotational basis often leave region and move to their home places. This makes the share of retirees in the YNAO significantly lower than in the country (Table 2).

Table 2. The number of retirees in the YNAO and in the Russian Federation.

\begin{tabular}{|l|c|c|c|c|c|c|c|c|c|}
\hline & $\mathbf{2 0 0 5}$ & $\mathbf{2 0 1 0}$ & $\mathbf{2 0 1 2}$ & $\mathbf{2 0 1 3}$ & $\mathbf{2 0 1 4}$ & $\mathbf{2 0 1 5}$ & $\mathbf{2 0 1 6}$ & $\mathbf{2 0 1 7}$ & $\mathbf{2 0 1 8}$ \\
\hline \multicolumn{8}{|c|}{ Retirees number, million people } \\
\hline Russia & 38.3 & 39.7 & 40.5 & 41.0 & 41.4 & 42.7 & 43.1 & 45.7 & 46.1 \\
\hline YNAO & 0.09 & 0.11 & 0.11 & 0.12 & 0.13 & 0.13 & 0.13 & 0.13 & 0.14 \\
\hline \multicolumn{1}{|c|}{ Retirees number per 1 thousand population } \\
\hline Russia & 267.5 & 277.9 & 283.0 & 285.5 & 287.9 & 291.6 & 294.1 & 318.7 & 314.0 \\
\hline YNAO & 169.8 & 211.9 & 219.9 & 230.0 & 238.4 & 249.5 & 256.2 & 261.0 & 264.1 \\
\hline
\end{tabular}

In addition, in the YNAO, the share of retirees in the total amount of social benefits is lower due to different types of benefits and social assistance. The reason are an active 
social responsibility policy among local enterprises and municipal authorities. Also plays role the fact that in the conditions of the North, many segments of the population have needs for additional protection from local authorities (Table 3 ).

Table 3. Structure of social payments in the YNAO and in the Russian Federation.

\begin{tabular}{|l|c|c|c|c|c|}
\hline & $\begin{array}{c}\text { Pension } \\
\text { payments }\end{array}$ & $\begin{array}{c}\text { Social } \\
\text { benefits }\end{array}$ & Scholarships & $\begin{array}{c}\text { Insurance } \\
\text { payments }\end{array}$ & $\begin{array}{c}\text { Other } \\
\text { payments }\end{array}$ \\
\hline \multicolumn{7}{|c|}{$\mathbf{2 0 0 5}$} \\
\hline Russia & 71.5 & 17.9 & 0.6 & 9.9 & 0.1 \\
\hline YNAO & 62.2 & 32.9 & 0.2 & 4.7 & 0.0 \\
\hline \multicolumn{7}{|c|}{$\mathbf{2 0 1 3}$} \\
\hline Russia & 70.5 & 25.0 & 0.9 & 3.5 & 0.1 \\
\hline YNAO & 63.2 & 35.5 & 0.3 & 1.0 & 0.0 \\
\hline \multicolumn{7}{|l|}{$\mathbf{2 0 1 6}$} \\
\hline Russia & 71.4 & 24.7 & 0.8 & 3.1 & 0.0 \\
\hline YNAO & 61.5 & 35.0 & 0.2 & 3.3 & 0.0 \\
\hline
\end{tabular}

An important factor that has a significant impact on the content of social protection policies in the YNAO is the remoteness of the region from large cities. Because of this, as well as the high cost of living, poor citizens in the region find themselves in a much more difficult situation than people with the same income in other regions of the country. Living cost for them is much higher, and the remoteness of the region from the densely populated parts of the country prevent them to change their place of residence quickly. In addition, they are distant from their relatives, who could assist them. Part of people who has come to the YNAO to earn money, do not have any social contacts and might be in a very difficult situation.

The same can be said about retirees with low pensions who did not leave the region after reaching retirement age. In other regions of Russia, as a rule, a person is aging in the social environment where he lived all his life. He lives with his family, may have some kind of property that has traditionally belonged to his family (country house or cottage). All this can be a great help upon retirement. Under the conditions of the YNAO, a person most often does not have this. Thus, if a pensioner does not receive a sufficiently big pension, he finds himself in an extremely difficult situation: there is not enough pension for living, and there are no additional sources of income, like any other support.

\section{Discussion}

In the YNAO, social protection policies are focused on the following areas:

1) social protection of children, childhood and teenage;

2) social protection of the working people;

3) social protection of disabled people;

4) and social protection of the family.

The successful indicators of the socio-economic development of the YNAO, its leadership in the general list of regions, the smaller scale of social problems do not mean that the system of social protection of the population does not require improvements. The district, like all other regions of the country, faced a number of strategic challenges. Nowadays, their influence on the overall situation in the region is not so great, but in the future, they can turn into systemic problems. These challenges include:

- an increase in life expectancy, an increase in the share of retirees, and, consequently, an increase in the burden on the Pension Fund;

- changes in the labor market and changes in the technological foundations of the organization of labor: as a result of the constant automation and computerization of 
production processes, we should expect further release of the workforce and exacerbation of the unemployment problem;

- and permanent existence of economic risks: the possibility of a worsening situation in the economy as a whole will lead to a decrease in the state's ability to implement social protection policy [9].

In the YNAO, as already noted, despite a relatively small proportion of citizens needs social support, almost $80 \%$ of the regional budget expenditures are social items. It is obvious that the social protection system first of all needs to increase the effectiveness of the funds spent, as well as a certain reorganization, taking into account all the challenges that it faces.

The key directions of the social protection system transformation in the YNAO can be represented as follows.

Development of regulatory support. Fast changes in social protection and transience of the situation requires constantly refining of the regulatory documents. In particular, there is a need to delimit the powers and responsibilities of federal and local authorities.

Improving the targeting of social services. The massive provision of social assistance leads to the fact that part of it spent inefficiently. The targeting principle will help to spend resources on assisting those who really need it.

Engagement of public organizations. The main functions of social protection are assigned to the federal and regional social protection structures. At the same time, the public movement, volunteer organizations in the Russian Federation have already sufficiently developed to perform a number of functions, at least, organizational and informational.

'Poverty Prevention'. The main strategic goal of social protection should be not so much the counteraction to negative social phenomena as the creation of conditions for such phenomena not to expand. That is, the emphasis should be placed not only and not so much on social assistance, as on the prevention of negative phenomena.

Foreign research [10-12] shows that, with a general increase in life expectancy, it is necessary to direct efforts to involve retirees in labor activity. An aspect of this direction of social policy includes an important educational element that raises a whole layer of problems:

- lifelong learning,

- advanced training and retraining,

- and obtaining a second / third profession in adulthood.

All this can help retirees to remain in demand on the labor market longer and, accordingly, increase the budget revenues due to deductions from the wage fund and the income of individuals.

The inability of the region to maintain control over the social situation in its territory can generate serious long-term threats. Management efficiency is especially weakened in out-of-center sparsely populated and rapidly degrading settlements. It is necessary to create a strong legal framework that provides the conditions for the sustainable development of the region through a more complete and balanced use of domestic resources [12].

\section{Conclusion}

At the regional level, the main burden is on supporting the necessary infrastructure, as well as organizing direct work with socially vulnerable citizens. This is the main feature of the regional social protection system. In regions such as the YNAO, regional authorities have an additional burden due to the specifics of economic and social life. Despite the well-being of the majority of the population, the remoteness of the region, the high cost of living and the high cost of maintaining infrastructure facilities make the task of supporting socially 
vulnerable people much more difficult and costly than in other regions. All this creates additional risks for the regional level of governance and determines the need to apply additional measures to shape the sustainable development of the social sphere in the region in the search for additional sources of funding and participants of the social protection system of population.

\section{References}

1. T.S. Sobol, Bulletin of Moscow State University named after S. Yu. Witte. Series 1: Economics and Management 2(25), 7-14 (2018)

2. V.S. Kudryashov, Petersburg Economic Journal 1, 28-33 (2014)

3. O.V. Pavlyukova, I.G. Khodzhaeva, I.P. Doroshina, Internet-journal Naukovedenie 3, 3-13 (2014)

4. Bogdanova O.Yu. The role of state programs in the system of social protection of the region. Scientific works of SWorld 15, 46-49 (2015)

5. I. I. Kochanowskaya, Y.V. Nazarenko, Bulletin of Moscow State University named after S. Yu. Witte, Series 1: Economics and Management 2(25), 24-32 (2018)

6. V.G. Belomestnov, K.P. Khardaev, Problems of the modern economy 1, 51-59 (2017)

7. E. Ganebnykh, T. Burtseva, A. Petuhova, A.Mottaeva, , E3S Web of Conferences, 91,08035, (2019) doi.org/10.1051/e3sconf /20199108035

8. Federal State Statistic Service, https://www.gks.ru/

9. I.V. Balynin, Finance and credit 30, 65-73 (2015)

10. H. Birkett, F. Carmichael, J. Duberley, Journal of Vocational Behaviour 103(B), 52-65 (2017)

11. F. Carmichael, M. Ercolani, The Journal of the Economics of Ageing 6, 163-175 (2015)

12. N. Elsebaie, E. Ganebnykh, M. Lunyakov, E3S Web of Conferences 110, 02155 (2019)

13. O.N. Bykova, L.G. Rudenko, Economy and entrepreneurship 1(102), 682-686 (2019) 